\title{
Metal Enolates - Enamines - Enol Ethers: How Do Enolate Equivalents Differ in Nucleophilic Reactivity?
}

\author{
Artem I. Leonov' \\ Daria S. Timofeeva \\ Armin R. Ofial* (D) \\ Herbert Mayr* (D)
}

Department Chemie, Ludwig-Maximilians-Universität München, Butenandtstraße 5-13, 81377 München, Germany

ofial@Imu.de

Herbert.mayr@cup.Imu.de

A contribution of Physical Organic Chemistry to systematizing Organic Synthesis. Cordial congratulations on the occasion of the Golden Anniversary of Synthesis.

Published as part of the 50 Years SYNTHESIS - Golden Anniversary Issue

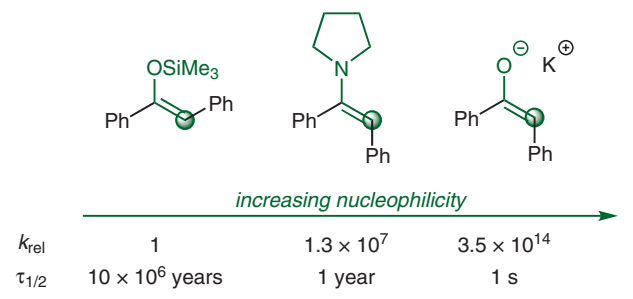

Received: 23.11.2018

Accepted after revision: 27.11.2018

Published online: 08.01 .2019

DOI: 10.1055/s-0037-1611634; Art ID: ss-2018-z0787-fa

License terms: CCO

Abstract The kinetics of the reactions of trimethylsilyl enol ethers and enamines (derived from deoxybenzoin, indane-1-one, and $\alpha$-tetralone) with reference electrophiles ( $p$-quinone methides, benzhydrylium and indolylbenzylium ions) were measured by conventional and stoppedflow photometry in acetonitrile at $20^{\circ} \mathrm{C}$. The resulting second-order rate constants were subjected to a least-squares minimization based on the correlation equation $\lg k=s_{N}(N+E)$ for determining the reactivity descriptors $N$ and $s_{N}$ of the silyl enol ethers and enamines. The relative reactivities of structurally analogous silyl enol ethers, enamines, and enolate anions towards carbon-centered electrophiles are determined as $1,10^{7}$, and $10^{14}$, respectively. A survey of synthetic applications of enolate ions and their synthetic equivalents shows that their behavior can be properly described by their nucleophilicity parameters, which therefore can be used for designing novel synthetic transformations.

Key words alkylation, enols, kinetics, linear free energy relationship, reactivity scales

Enolate equivalents are among the most important reagents in organic and biochemistry. ${ }^{2-11}$ In organic synthesis, they are commonly employed as metal enolates or as their synthetic equivalents, enamines or enol ethers, depending on the electrophilicity of the corresponding reaction partners. The qualitative ranking of reactivity - metal enolate > enamine > enol ether - is well known. A quantitative comparison has been hampered by the fact, however, that electrophiles, which are suitable for kinetic studies with enolate ions, have such low electrophilicities that they do not react with enamines and enol ethers. On the other hand, electrophiles, suitable for studying the kinetics of their reactions with enamines or enol ethers, are so reactive that they will generally undergo unselective diffusion-controlled reactions with alkali enolates. How can this dilemma be overcome?

In previous years, we have established a series of colored reference electrophiles covering a reactivity range of 32 orders of magnitude, which are suitable for studying the reactivities of nucleophiles of widely differing reactivity. ${ }^{12-15}$ By using equation 1, in which electrophiles are characterized by one parameter $E$, and nucleophiles are characterized by the solvent-dependent nucleophilicity parameter $N$ and susceptibility $s_{N}$, we have so far parameterized more than 300 electrophiles and 1100 nucleophiles. ${ }^{16}$

$$
\lg k_{20}{ }^{\circ} \mathrm{C}=s_{N}(E+N)
$$

Equation 1

We now report on the reactivities of the enolate equivalents depicted in Figure 1, which allow us to quantitatively compare the previously reported nucleophilicities of potassium enolates with those of structurally analogous enamines and enol ethers. We will furthermore demonstrate that the combination of nucleophilicity parameters for enolates, enamines, and silyl enol ethers with the reactivity parameters $E$ of electrophiles provides an ordering principle for enolate chemistry.
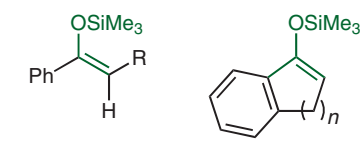

$$
1 \mathrm{a}(\mathrm{R}=\mathrm{Ph})
$$$$
\begin{array}{rl}
1 & a(R=P h) \\
1 b & =M e)
\end{array}
$$

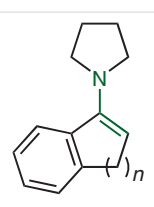

2a $(n=1)$
Figure 1 Structures of silyl enol ethers $\mathbf{1 a} \mathbf{a}-\mathbf{d}$ and enamines $\mathbf{2 a}, \mathbf{b}$ investigated as enolate equivalents in this work 
Table 1 lists the indolylbenzylium ions 3a-c, benzhydrylium ions $\mathbf{3 d}-\mathbf{l}$, and quinone methides $\mathbf{3 m - \mathbf { m }}$, which were employed as reference electrophiles for the kinetic measurements.

\section{Product Studies}

The reactions of the silyl enol ethers $\mathbf{1 a}, \mathbf{1 c}$, and $\mathbf{1 d}$ with benzhydrylium or indolylbenzylium tetrafluoroborates initially yielded siloxy-substituted carbenium ions 4 . Fast sub- sequent desilylation then afforded ketones $\mathbf{5 a}$ a-c (Scheme 1 ), which were purified by column chromatography and characterized by NMR spectroscopy and mass spectrometry. Electrophilic attack of the prochiral carbocation 3a led to a mixture of two diastereomers of $\mathbf{5 c}$ in a ratio of ca. 1:1.33 (determined by NMR spectroscopy).

Electrophilic attack of the benzhydrylium tetrafluoroborate $\mathbf{3 g}$ on the enamine $\mathbf{2 b}$ led to formation of the iminium salt $\mathbf{6}$. Its hydrolysis gave the ketone $\mathbf{5 d}$, which was purified by column chromatography and isolated in moderate yield (Scheme 2).

\section{Biographical Sketches}
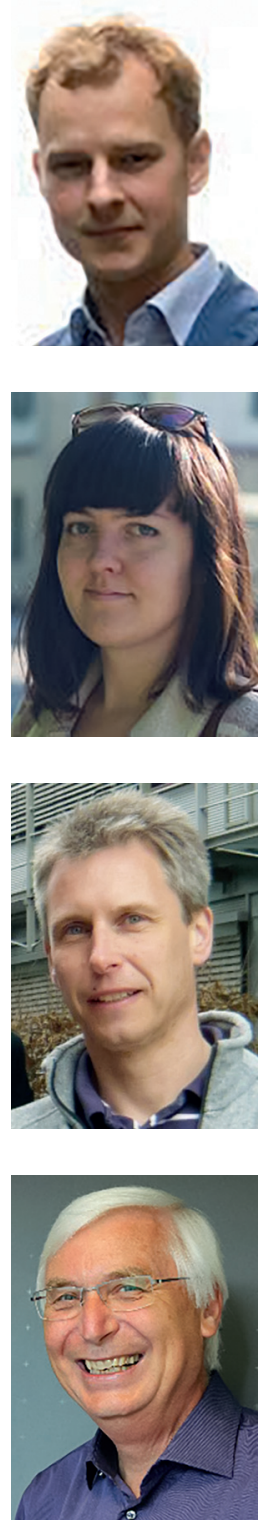

Artem I. Leonov obtained a diploma in chemical engineering at the Mendeleev University of Chemical Technology of Russia (Moscow) before moving to Ludwig-Maximilians-Universität München (LMU) (Germany) in 2013, where he received his

Daria S. Timofeeva received her diploma in chemical engineering at the Mendeleev University of Chemical Technology of Russia (Moscow), with her final research project on phero-

Armin R. Ofial studied chemistry at the Technical University of Darmstadt (Germany), where he graduated with Prof. Alarich Weiss in 1991 (diploma) and received his doctoral degree with Prof. Herbert Mayr in 1996. In

Herbert Mayr obtained his Ph.D. in 1974 (Prof. R. Huisgen, LMU München). After postdoctoral studies (Prof. G. A. Olah, Cleveland, USA), he completed his habilitation in 1980 (Prof. P. von R. Schleyer, Erlangen). After professorships in Lübeck and Darmstadt, he returned to the doctoral degree in the group of Dr. Ofial on physical organic chemistry. His research focused on kinetic and mechanistic studies of carbon nucleophiles such as Grignard reagents, carbanions, enol ethers and enamines for the further devel-

mone total synthesis conducted at the All-Russian Plant Quarantine Center. In 2014, she started her doctoral studies in the group of Prof. Herbert Mayr at the LMU München (Germany), opment of the Munich reactivity scale. In 2018, he joined the group of Prof. Lee Cronin in Glasgow (UK) to work on an automatic synthetic platform and the implementation of kinetic analysis for reaction optimization.

where her work has focused on the study of the reactivity of enamines and electrophilic fluorinating reagents.

1997, he moved as a research associate to the Ludwig-Maximilians-Universität München (Germany). In 2009, he established his research group at the LMU München and habilitated in 2013. Armin's research inter-

LMU München in 1996. He received the Alexander von Humboldt Honorary Fellowship of the Foundation for Polish Science (2004) and the Liebig Denkmünze (GDCh, 2006). He is a member of the Bavarian Academy of Sciences and the Leopoldina - National Academy ests include reactions of iminium ions, kinetics, and selective $\mathrm{C}-\mathrm{H}$ bond functionalizations. He received the Thieme Chemistry Journals Award in 2012. of Sciences. His research interests comprise quantitative approaches to organic reactivity including mechanisms of organocatalytic reactions and the theory of polar organic reactions. 
Table 1 Indolylbenzylium lons 3a-c, Benzhydrylium lons 3d-I and Quinone Methides 3m-o Employed as Reference Electrophiles in this Study

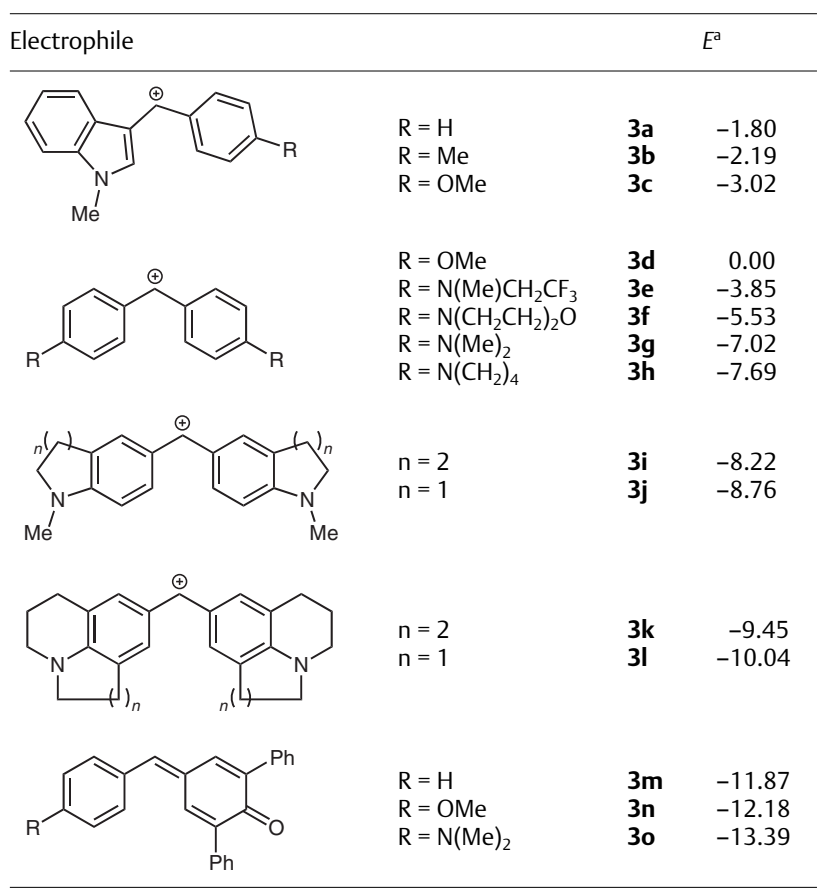

${ }^{\mathrm{a}}$ Electrophilicity parameters $E$ were taken from refs 12, 13, 17, and 18.

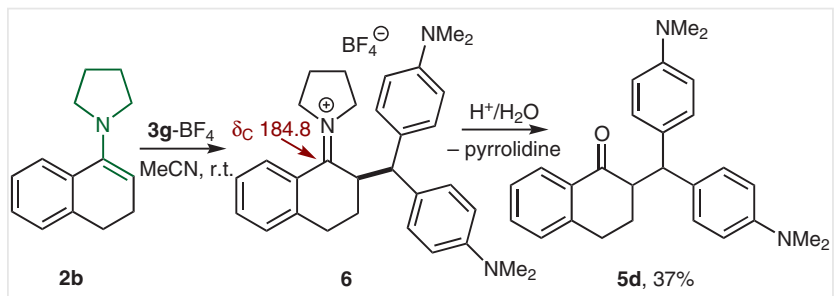

Scheme 2 Reaction of the enamine $\mathbf{2} \mathbf{b}$ with reference electrophile $\mathbf{3 g}$ $\mathrm{BF}_{4}\left(\mathrm{NMR}\right.$ chemical shift $\delta$ in $\mathrm{ppm}, \mathrm{CD}_{3} \mathrm{CN}, 100 \mathrm{MHz}$ )

The reaction of the enamine $2 \mathbf{a}$ with the quinone methide $\mathbf{3 m}$ furnished the zwitterion $\mathbf{7}$, which tautomerized, and within 30 minutes, quantitatively yielded the product 8 as determined by NMR spectroscopy (Scheme 3).

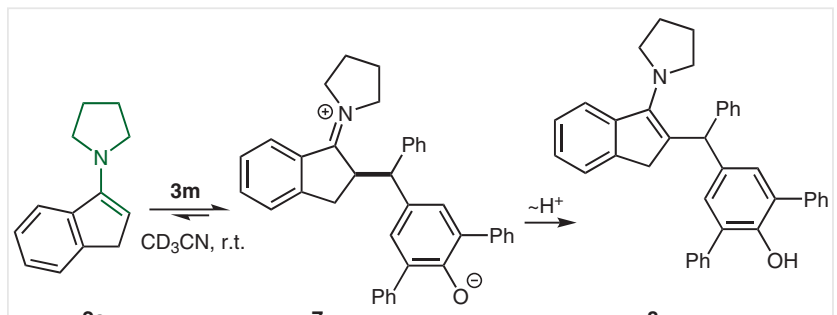

Scheme 3 Reaction between enamine $2 \mathrm{a}$ and quinone methide $\mathbf{3 m}$<smiles>COc1ccc(C(C(=O)c2ccccc2)C(c2ccc(OC)cc2)c2ccc(OC)cc2)cc1</smiles>

$1 \mathrm{a}$

$4 a$

5 a, $95 \%$<smiles>COC1=CCc2ccccc21</smiles><smiles>COC1=CCCc2ccccc21</smiles>

$1 d$

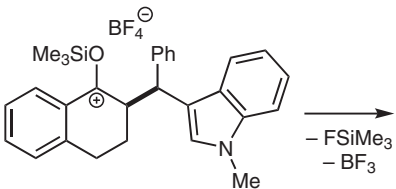

$4 c$<smiles>Cn1cc(C(c2ccccc2)C2CCc3ccccc3C2=O)c2ccccc21</smiles>

5c, $71 \%(d r 57 / 43)$

Scheme 1 Reactions of silyl enol ethers $\mathbf{1 a}, \mathbf{1 c}$, and $\mathbf{1 d}$ with reference electrophiles. Yields refer to isolated products 


\section{Kinetic Investigations}

The reactions of the silyl enol ethers 1a-d and enamines 2a,b with the reference electrophiles $\mathbf{3 a - n}$ were investigated in either acetonitrile or dichloromethane at $20{ }^{\circ} \mathrm{C}$ and monitored by UV-Vis spectroscopy at or close to the absorption maxima of the electrophiles (Table 2). To simplify the evaluation of the kinetic experiments, the nucleophiles were used in large excess (usually 8 equiv or more) to keep their concentrations almost constant throughout the reactions. The first-order rate constants $k_{\text {obs }}$ were derived by least-squares fitting of the exponential function $A_{\mathrm{t}}=$ $A_{0} \cdot \exp \left(-k_{\mathrm{obs}} t\right)+C$ to the time-dependent absorbances $A_{\mathrm{t}}$ of the electrophile. The second-order rate constants $k_{2}$, listed in Table 2, were obtained as the slopes of the linear correlations between $k_{\text {obs }}$ and the concentrations of the nucleophiles as exemplified in Figure 2 for the reaction of the silyl enol ether 1a with the indolylbenzylium ion $\mathbf{3 a}$.
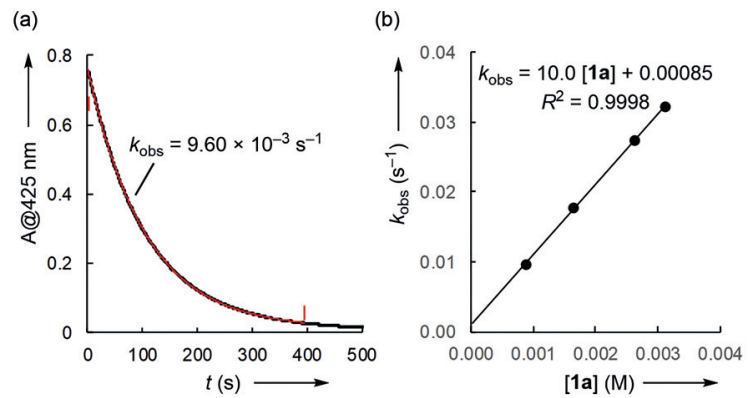

Figure 2 (a) Exponential decay of the absorbance $A$ (at $425 \mathrm{~nm}$ ) during the reaction of $3 \mathbf{a}\left(9.27 \times 10^{-5} \mathrm{M}\right)$ with $1 \mathbf{a}\left(8.82 \times 10^{-4} \mathrm{M}\right)$ in acetonitrile at $20^{\circ} \mathrm{C}$. (b) Correlation of the first-order rate constants $k_{\text {obs }}$ with the concentrations of the nucleophile $\mathbf{1 a}$

\section{Correlation Analysis}

The rate constants $\left(\lg k_{2}\right)$ for the reactions of the silyl enol ethers $\mathbf{1}$ and enamines $\mathbf{2}$ with indolylbenzylium ions $\mathbf{3 a}-\mathbf{c}$, benzhydrylium ions $\mathbf{3 e - 1}$, and quinone methides $\mathbf{3 m}$ n correlate linearly with the electrophilicity parameters $E$ of $\mathbf{3 a - n}$ (Figure 3). Therefore, equation 1 is applicable, and the $N$ and $s_{\mathrm{N}}$ parameters for the nucleophiles $\mathbf{1}$ and $\mathbf{2}$ (Table 2 ) were derived from the intercepts and slopes of these correlations.

\section{Structure-Reactivity Relationships}

The narrow range of the nucleophile-specific susceptibilities $\left(0.82<s_{\mathrm{N}}<0.94\right)$ for the silyl enol ethers 1 indicates that the relative reactivities of these $\pi$-systems depend only
Table 2 Second-Order Rate Constants $k_{2}$ for the Reactions of the Silyl Enol Ethers $\mathbf{1}$ and Enamines $\mathbf{2}$ with Reference Electrophiles $\mathbf{3}$ in MeCN at $20^{\circ} \mathrm{C}$

\begin{tabular}{|c|c|c|c|c|}
\hline Nucleophile & $N\left(s_{N}\right)^{a}$ & Electrophile & $\lambda(\mathrm{nm})^{\mathrm{b}}$ & $k_{2}\left(\mathrm{M}^{-1} \mathrm{~s}^{-1}\right)$ \\
\hline $1 a$ & $3.00(0.83)$ & $\begin{array}{l}3 a \\
3 b \\
3 c\end{array}$ & $\begin{array}{l}425 \\
431 \\
474\end{array}$ & $\begin{array}{l}1.00 \times 10^{1} \\
4.77 \\
9.63 \times 10^{-1}\end{array}$ \\
\hline 1a (in $\mathrm{CH}_{2} \mathrm{Cl}_{2}$ ) & $3.13(0.82)$ & $\begin{array}{l}3 a \\
3 c\end{array}$ & $\begin{array}{l}425 \\
492\end{array}$ & $\begin{array}{l}1.24 \times 10^{1} \\
1.23\end{array}$ \\
\hline $1 b$ & $5.18(0.94)$ & $\begin{array}{l}3 a \\
3 b \\
3 c\end{array}$ & $\begin{array}{l}413 \\
434 \\
471\end{array}$ & $\begin{array}{l}1.32 \times 10^{3} \\
7.26 \times 10^{2} \\
1.00 \times 10^{2}\end{array}$ \\
\hline $1 c$ & $7.32(0.82)$ & $\begin{array}{l}3 a \\
3 b \\
3 c \\
3 e \\
3 f \\
3 g\end{array}$ & $\begin{array}{l}413 \\
434 \\
471 \\
586 \\
612 \\
605\end{array}$ & $\begin{array}{l}2.59 \times 10^{4} \\
1.39 \times 10^{4} \\
4.94 \times 10^{3} \\
8.94 \times 10^{2} \\
3.39 \times 10^{1} \\
1.36\end{array}$ \\
\hline 1d & $5.06(0.91)$ & $\begin{array}{l}3 a \\
3 b \\
3 c \\
3 f\end{array}$ & $\begin{array}{l}413 \\
434 \\
471 \\
612\end{array}$ & $\begin{array}{l}8.41 \times 10^{2} \\
3.53 \times 10^{2} \\
9.29 \times 10^{1} \\
3.48 \times 10^{-1}\end{array}$ \\
\hline $2 a$ & $15.27(0.93)$ & $\begin{array}{l}3 k \\
31 \\
3 m \\
3 n\end{array}$ & $\begin{array}{l}635 \\
632 \\
384 \\
414\end{array}$ & $\begin{array}{l}2.53 \times 10^{5} \\
7.73 \times 10^{4} \\
1.57 \times 10^{3} \\
7.00 \times 10^{2}\end{array}$ \\
\hline $2 b$ & $14.09(0.66)$ & $\begin{array}{l}3 \mathbf{g} \\
3 \mathbf{h} \\
3 \mathbf{i} \\
3 \mathbf{j} \\
3 \mathbf{k}\end{array}$ & $\begin{array}{l}605 \\
612 \\
620 \\
616 \\
635\end{array}$ & $\begin{array}{l}4.34 \times 10^{4} \\
1.75 \times 10^{4} \\
8.87 \times 10^{3} \\
3.03 \times 10^{3} \\
1.14 \times 10^{3}\end{array}$ \\
\hline
\end{tabular}

a From the second-order rate constants $k_{2}$ in this Table by using equation 1 and the electrophilicity parameters $E$ listed in Table 1.

b Monitored wavelength.



Figure 3 Correlations of the second-order rate constants $\left(\lg k_{2}\right)$ for the reactions of the enolate equivalents $\mathbf{1}$ and $\mathbf{2}$ with the electrophiles $\mathbf{3}$ in acetonitrile at $20^{\circ} \mathrm{C}$ with the electrophilicity parameters $E$ of 3

slightly on the nature of the attacking electrophiles. Therefore, the reactivities towards any of the carbenium ions 3a1 reflect general structure-reactivity trends.

Table 2 shows that the reactions of $\mathbf{1 a}$ with $\mathbf{3 a}$ and $\mathbf{3 c}$ proceed only 1.3 times faster in dichloromethane than in acetonitrile. Because of this small difference, solvent effects will be neglected in the following discussions. 
Figure 4 compares the reactivities of the silyl enol ethers $\mathbf{1 a}$ and $\mathbf{1 b}$ towards indolylbenzylium ion $\mathbf{3 b}$ with the previously reported reactivity of the acetophenone-derived silyl enol ether 9a towards the same electrophile. ${ }^{12}$ Introduction of a methyl group at the site of electrophilic attack $(\mathbf{9 a} \rightarrow$ 1b) decreases the reactivity by a factor of 10 , whereas introduction of a phenyl group at this position $(\mathbf{9 a} \rightarrow \mathbf{1 a})$ reduces nucleophilic reactivity by three orders of magnitude.



$$
\begin{aligned}
& 9 a \quad 1 b \quad 1 a \\
& k_{2}(3 b)\left(M^{-1} \mathrm{~s}^{-1}\right) \quad 7.4 \times 10^{3, a} \quad 7.3 \times 10^{2, b} \quad 4.8^{b} \\
& \begin{array}{llll}
k_{\text {rel }} & 1 & 1 / 10 & 1 / 1520
\end{array}
\end{aligned}
$$

Figure 4 Structural effects on the nucleophilic reactivities of silylated

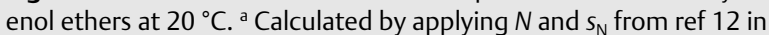
equation 1 (for 9 a in $\mathrm{CH}_{2} \mathrm{Cl}_{2}: \mathrm{N}=6.22, \mathrm{~s}_{\mathrm{N}}=0.96$ ). ${ }^{\text {b Second-order rate }}$ constant in MeCN from Table 2

Benzoannulation of the cyclic enol ether $\mathbf{9 b}$ increases its reactivity towards $\mathbf{3 g}$ by a factor of $3.9(\mathbf{9 b} \rightarrow \mathbf{1 c})$ (Figure 5$)$, whereas benzoannulation of 1-(trimethylsiloxy)cyclohexene (9c) does not have a significant effect on the reactivity $(\mathbf{9 c} \rightarrow \mathbf{1 d})$. As a consequence, the previously reported reactivity preference of the cyclopentenyl over the cyclohexenyl silyl enol ether by a factor of 20 increases to almost two orders of magnitude for the benzoannulated analogs (1c vs 1d). As mentioned above, the small reactivity difference of 1a in acetonitrile and dichloromethane (Table 2) allows us to neglect the fact that the data for $\mathbf{9 b}$ and $\mathbf{9 c}$ in Figure 5 refer to dichloromethane whereas those for $\mathbf{1 c}$ and $\mathbf{1 d}$ refer to acetonitrile solutions.

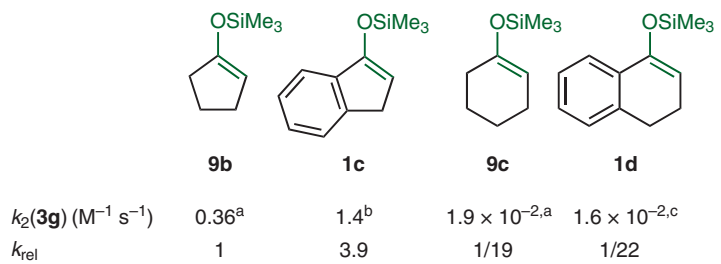

Figure 5 Effect of benzoannulation on the nucleophilic reactivities of 1 -(trimethylsiloxy)cycloalkenes at $20^{\circ} \mathrm{C}$. a Second-order rate constant (in dichloromethane) from ref $12 .{ }^{\mathrm{b}}$ Second-order rate constant in MeCN from Table 2. ' Calculated for the reaction $\mathbf{1 d}+\mathbf{3 g}$ (in MeCN) from data in Tables 1 and 2 by using equation 1

Figure 6 compares the nucleophilic reactivities of enamines, which are structural analogs of the silylated enol ethers in Figure 5. As in the enol ether series, the cyclopentene derivative 10a is one order of magnitude more reactive than the cyclohexene derivative $\mathbf{1 0 b} .{ }^{19}$ While benzoannulation of the cyclopentenylamine $\mathbf{1 0 a}(\rightarrow \mathbf{2 a})$ has a negligible effect on nucleophilic reactivity, benzoannulation of the corresponding cyclohexene derivative $\mathbf{1 0 b}(\rightarrow \mathbf{2 b})$ reduces the nucleophilicity by a factor of 69 (in acetonitrile). Due to steric effects, coplanarity of the pyrrolidino ring with the $\mathrm{C}=\mathrm{C}$ double bond of the enamine is more disturbed in $\mathbf{2 b}$ than in $\mathbf{2 a} .^{20}$

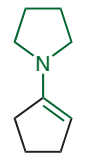

$10 a$

$k_{2}(3 \mathbf{k})\left(\mathrm{M}^{-1} \mathrm{~s}^{-1}\right) \quad 3.3 \times 10^{5, \mathrm{a}}$

$k_{\text {rel }}$

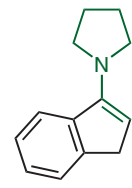

$2 a$

$2.5 \times 10^{5, b}$

$1 / 1.3$

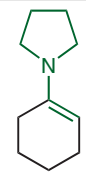

$10 b$

$4.6 \times 10^{4, a}$

$\left(7.6 \times 10^{4}\right)^{\mathrm{c}}$

$1 / 7.2$

$(1 / 4.3)$

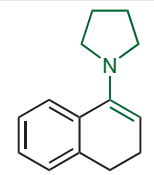

$2 b$

$1.1 \times 10^{3, \mathrm{~b}}$

$1 / 300$
Figure 6 Effect of benzoannulation on the nucleophilic reactivities of

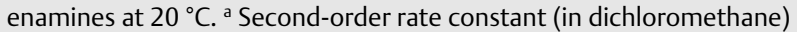
from ref 19. ${ }^{b}$ Second-order rate constant (in MeCN) from Table 2. ${ }^{c}$ Second-order rate constant (in $\mathrm{MeCN}$ ) from ref 21

With the newly determined nucleophilicity parameters, it is now possible to compare directly the nucleophilic reactivity of the enolate ion $\mathbf{1 1}^{22}$ with the reactivities of its structurally related equivalents $\mathbf{1 a}$ and $\mathbf{1 0} \mathbf{c}^{23}$ (Figure 7). When the $N$ and $s_{\mathrm{N}}$ parameters of $1 \mathbf{a}$ and $10 \mathbf{c}$ are used to calculate the rate constants of their reactions with quinone methide $30(E=-13.39)$, the most reactive electrophile used for the characterization of the enolate ion 11, one finds that the enamine $10 \mathrm{c}$ is $10^{7}$ times less reactive than $\mathbf{1 1}$ and that the enol ether $\mathbf{1 a}$ is another $10^{7}$ times less reactive than the enamine 10c. In a dilute solution, in which the reaction of the enolate ion $\mathbf{1 1}$ would proceed within one second, the corresponding reaction of the enamine 10c would require one year, and the silyl enol ether 1a would reach the same degree of conversion after ten million years.
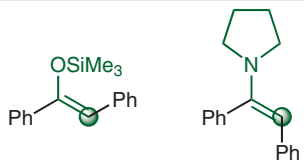

$1 a$

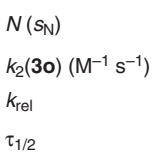

$$
3.00(0.83)
$$$$
2.4 \times 10^{-9}
$$$$
1
$$$$
10 \times 10^{6} \text { years }
$$<smiles>O=C([O-])c1ccccc1</smiles>

11 $10 c$

$11.66(0.82)^{\mathrm{a}}$

$3.8 \times 10^{-2}$

$1.6 \times 10^{7}$

1 year

$7.2 \times 10^{5}$

$3.0 \times 10^{14}$

$1 \mathrm{~s}$

Figure 7 Comparison of the nucleophilic reactivities (at $20^{\circ} \mathrm{C}$ ) of the deprotonated deoxybenzoin $\mathbf{1 1}$ with its synthetic equivalents $\mathbf{1 a}$ and 10c. ${ }^{\mathrm{a}}$ In MeCN, from ref $23 .{ }^{\mathrm{b}}$ In DMSO, from ref 22

\section{Applications}

The nucleophilicity parameters determined in this investigation can now be combined with previously reported reactivity indices ${ }^{16}$ to rationalize the use of enolate ions and their synthetic equivalents in organic synthesis. Figure 8 depicts enolates, enamines, and silyl enol ethers with in- 
creasing nucleophilicity from bottom to top and electrophiles with increasing reactivities from top to bottom. Nucleophiles and electrophiles at the same level $(E+N \approx-3)$ react with a rate constant of ca. $0.004 \mathrm{M}^{-1} \mathrm{~s}^{-1}$ at $20^{\circ} \mathrm{C}$ (from equation 1 for a typical value of $s_{\mathrm{N}}=0.8$ ), which corresponds to a half reaction time of about 20 minutes for $0.2 \mathrm{M}$ solutions. If enolate ions and enamines are intermediates of catalytic processes, their lower concentration has to be taken into account when estimating the reaction times.

\section{Reactions of Enolate lons}

Reactions of enolate ions with C-centered electrophiles represent important methods for generating new carboncarbon bonds. ${ }^{2-11,24-29}$ The non-stabilized enolate ions at the top of Figure 8 react with all electrophiles shown on the right. Due to their high reactivity, lithium enolates are useful reagents for cross-aldol reactions with ketones and aldehydes (as shown for $\mathbf{1 2}$ in Scheme 4a). ${ }^{30}$ In reactions with Michael acceptors (e.g., with 13), they may be used as preformed anions or may be generated in situ by treatment of the corresponding $\mathrm{CH}$ acids with catalytic amounts of Brønsted bases (Scheme 4b).31,32 Acceptor-substituted enolate ions, such as cyano-, acetyl-, alkoxycarbonyl- and phenylsulfonyl-substituted enolate ions, react at or slightly above room temperature with a large variety of Michael acceptors with $E>-23$ (as exemplified for the combination $\mathbf{1 4}+\mathbf{1 5}$ in Scheme $4 \mathrm{c}),{ }^{33-35}$ but we are not aware of reactions of such stabilized enolate ions with weak electrophiles, such as the cinnamic ester $\mathbf{1 6}(E=-24.5)$.

a)

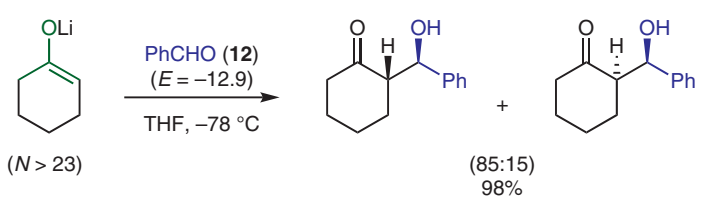

b)<smiles>O=C(Cc1ccccc1)c1ccccc1</smiles>

$$
\begin{gathered}
11-\mathrm{H} \\
\text { (for } 11: N=23.2 \text { ) }
\end{gathered}
$$
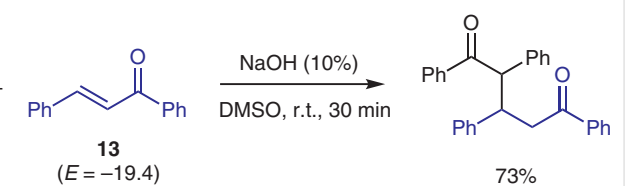

c)


$(E=-19.1)$

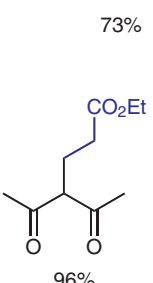

Scheme 4 Enolate ions: (a) in a cross-aldol reaction with benzaldehyde (12) (from ref 30 ), (b) generated from $11-\mathrm{H}$ in a reaction with the $\mathrm{Mi}$ chael acceptor 13 (from ref 31 ), and (c) generated from $14-\mathrm{H}$ in a reaction with ethyl acrylate (15) (from refs 34 and 35)
Pyridinium-substituted enolate ions (that is, acyl-substituted pyridinium ylides) readily react with Michael acceptors of $E>-25$ to give zwitterions, which usually cyclize with formation of 1,2,3,8a-tetrahydroindolizines (Scheme $5 a)^{36,37}$ or cyclopropanes. ${ }^{38,39}$
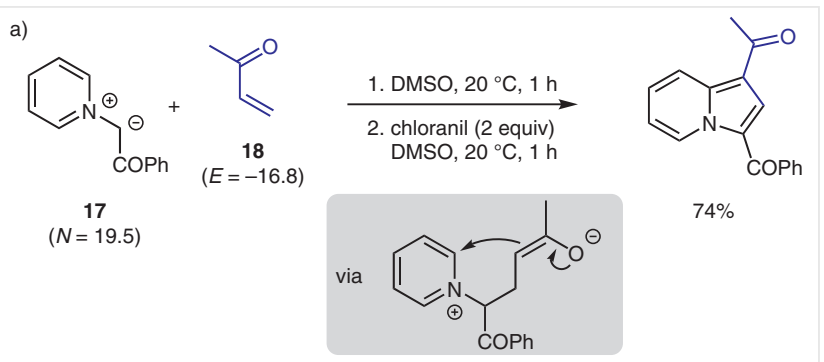

b)

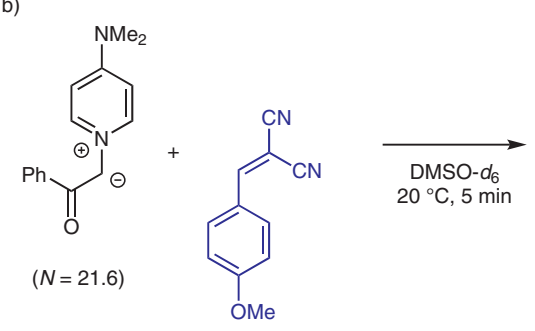

$(E=-10.8)$

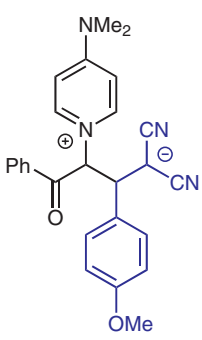

quant. (NMR)
Scheme 5 Reactions of pyridinium ylides with Michael acceptors: (a) from ref 37 , (b) from ref 40

Monitoring the reaction of equimolar amounts of a 4(dimethylamino)-substituted pyridinium ylide with $p$-methoxybenzylidene malononitrile by NMR spectroscopy showed the quantitative formation of a betaine, which did not cyclize under the reaction conditions due to the stabilizing effect of the two cyano groups at the carbanionic center (Scheme $5 b){ }^{40}$

\section{Reactions of Enamines}

Pyrrolidine-derived enamines, such as 1-(cyclopent-1en-1-yl)pyrrolidine (10a) or $\mathbf{1 0 b}$, have been reported to react with a large variety of Michael acceptors with $E>-20$ (Scheme 6a). ${ }^{41-43}$ Whereas the reaction with the weakly electrophilic acrylonitrile (19) required 12 hours refluxing in dioxane, ${ }^{41}$ the reactions with more electrophilic nitroalkenes ${ }^{42}$ and the strong electrophile $\mathbf{2 0}$ proceed rapidly at room temperature. ${ }^{43}$ The nucleophilic attack of enamines at the carbonyl group of aromatic and aliphatic aldehydes yields $\alpha, \beta$-unsaturated ketones through condensation and subsequent aqueous workup (Scheme $6 \mathrm{~b}$ ). ${ }^{44}$ 




Figure 8 Ranking of C-nucleophiles on the nucleophilicity scale and the scope of their reactions with electrophiles. Enolate ions and their synthetic equivalents (on the left-hand side) can be expected to react with all electrophiles (on the right-hand side) located at the same level of the respective nucleophile or below (nucleophilicity parameters $N$ in acetonitrile if not mentioned otherwise, $N$ and $E$ were taken from ref 16 ) 
a)<smiles>C=COC(=O)C1CCCCC1</smiles>

$$
\underset{\text { aq workup }}{\stackrel{\text { reflux, dioxane }}{\longrightarrow}}
$$<smiles>N#CCCC1CCCCC1=O</smiles>

$80 \%$

$(N=14.9)$

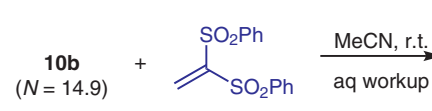
20
$(E=-7.5)$<smiles>O=C1CCCCC1CC([SeH])Oc1ccccc1</smiles>

$63 \%$

b)<smiles>C1=C(N2CCOCC2)CCC1</smiles><smiles>O=Cc1ccccc1</smiles><smiles>CC(C)C1CC1</smiles><smiles>O=C1CCC/C1=C\c1ccccc1</smiles>
$84 \%$

$(N=13.4$ in $\mathrm{CH}_{2} \mathrm{Cl}_{2}$ )

$(E=-12.9)$

Scheme 6 Reactions of enamines with (a) Michael acceptors (for 19 from ref 41 ; for 20 from ref 43), and (b) aldehydes (from ref 44a)

Enamines (for example, $\mathbf{2 b}$ or $\mathbf{1 0 b}$ ) react with preformed iminium salts such as 21a and 21b in high yields under mild conditions to give the Mannich bases of $\alpha$-tetralone or cyclohexanone, respectively (Scheme 7). ${ }^{45,46}$

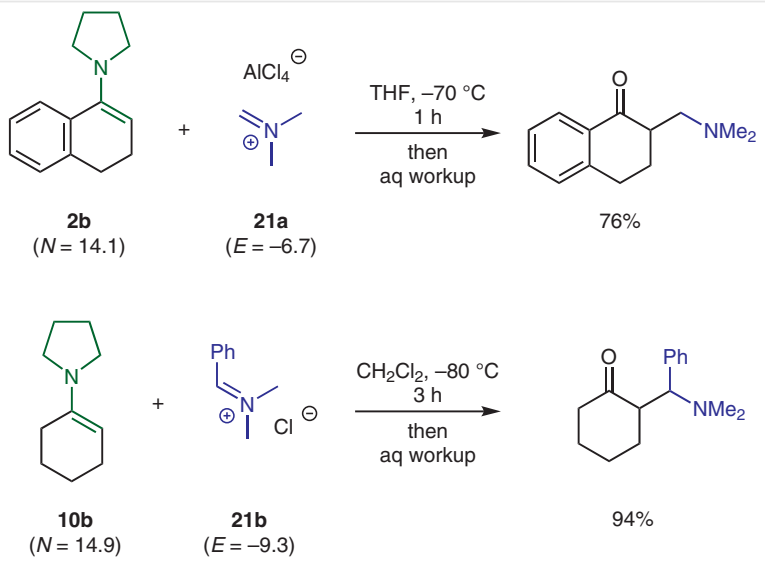

Scheme 7 Formation of Mannich bases through reactions of enamines with preformed iminium salts (from ref 45 )

Fast $\mathrm{F}^{+}$transfer reactions to colored enamines, such as 10c, were used to quantify the reactivity of electrophilic fluorinating N-F reagents with $-10.5<E<-5$ [such as NSFI (22) in Scheme 8a]. ${ }^{47}$ The same types of enamines were used to characterize $\mathrm{F}_{3} \mathrm{CS}^{+}$and $\mathrm{F}_{2} \mathrm{CHS}^{+}$transfer agents, such as the saccharin derivative $\mathbf{2 3}$ (Scheme $8 \mathrm{~b}$ ). ${ }^{48}$

Enamine activation has emerged as a widely applicable organocatalytic method for the $\alpha$-functionalization of carbonyl compounds. ${ }^{49-56}$ List et al. discovered that enantioselective aldol reactions between acetone and various aldehydes proceed through conversion of the ketone into the<smiles>N#[W+]=NC1CCCN1C(=Cc1ccccc1)c1ccccc1</smiles>

b)



Scheme 8 Reactions of enamine 10c with electrophilic: (a) fluorinating (from ref 47), and (b) trifluoromethylthiolating reagents (from ref 48)

corresponding proline-derived enamine intermediate (Scheme 9a).57,58 Subsequently proline-catalyzed threecomponent Mannich reactions with $\mathrm{N}$-arylimines ${ }^{59}$ and Michael additions to nitroolefins, such as $\mathbf{2 4}$ (Scheme 9b), ${ }^{60}$ were developed (at r.t., several hours of reaction time). a)

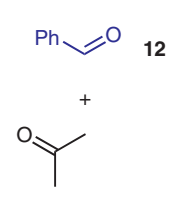

as co-solvent (20 vol\%)

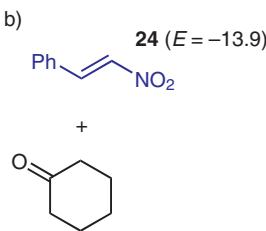

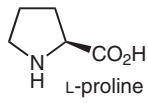



$62 \%$
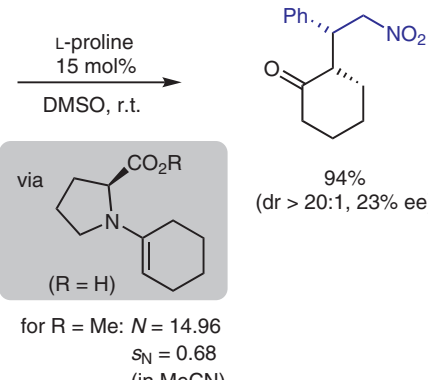

$94 \%$ $(\mathrm{dr}>20: 1,23 \%$ ee $)$

Scheme 9 Proline-catalyzed: (a) aldol reactions (from ref 57), and (b) Michael additions (from ref 60)

In particular, diarylprolinol silyl ethers introduced by Hayashi and Jørgensen have proven to be versatile catalysts for the stereoselective introduction of substituents at the $\alpha$ position of aldehydes. ${ }^{54,61,62}$ As indicated by the position of the 2-phenylacetaldehyde-derived enamine $\mathbf{1 0 d}(N=10.56$, $s_{\mathrm{N}}=1.01$ in $\mathrm{MeCN}$ ) in Figure $8,{ }^{63}$ structurally analogous enamines are such strong nucleophiles that they react with $\beta$-nitrostyrene (24) at $0{ }^{\circ} \mathrm{C}$ with excellent control of the ste- 
reoselectivity (Scheme 10a). ${ }^{64,65}$ The diphenylprolinol silyl ether-catalyzed reaction of 3-phenylpropanal with the less electrophilic methyl vinyl ketone (18) delivered only a moderate yield of the 1,5-dicarbonyl product with high enantioselectivity, even when a higher catalyst loading was used (Scheme 10b).64,66

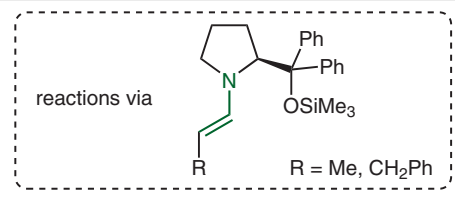

for $\mathrm{R}=\mathrm{Ph}: N=10.56, s_{N}=1.01$

$$
\text { a) }
$$

b)

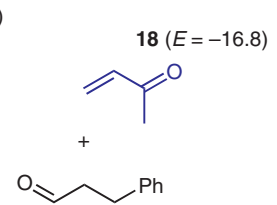

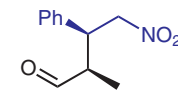

$85 \%$

(syn/anti 96:4, 99\% ee)
<smiles>CC(=O)CCC(C=O)Cc1ccccc1</smiles>

$52 \%(97 \%$ ee $)$
Scheme 10 Michael additions via Hayashi-Jørgensen-catalyst-derived enamines (from ref 64)

Cozzi and coworkers rationally designed enantioselective $\alpha$-alkylation reactions of aldehydes, in which in situ generated carbocations $\mathrm{R}^{\prime+}$ with electrophilicities $E$ between -1.5 and -7 were intercepted by enamines (e.g., by 10e in Figure 8) derived from aldehydes and MacMillan's imidazolidinone catalysts. ${ }^{67-70}$ The position of enamine $\mathbf{1 0 e}^{63}$ in Figure 8 is also in line with the observation that NFSI $(\mathbf{2 2})^{71}$ and 2,3,4,5,6,6-hexachlorocyclohexa-2,4-dien1-one (25) are suitable reagents for imidazolidinone-catalyzed $\alpha$-halogenations of aldehydes (Scheme 11). ${ }^{72,73}$

\section{Reactions of Enol Ethers}

Alkyl enol ethers have similar nucleophilic reactivities as structurally analogous silyl enol ethers (Scheme 12a), ${ }^{74}$ but are considerably less nucleophilic than enamines (see Figure 8). The use of alkyl enol ethers as enolate anion equivalents is rather limited, however, because of their tendency to undergo polymerization. In an extensive review, Hall demonstrated that highly electrophilic ethylene derivatives can initiate the ionic polymerization of alkyl enol ethers. ${ }^{75}$ Polymerization is avoided when 1,4-zwitterions are formed, which cyclize with formation of cyclobutanes, as studied in detail by Huisgen (Scheme $12 \mathrm{~b}$ ). ${ }^{76}$

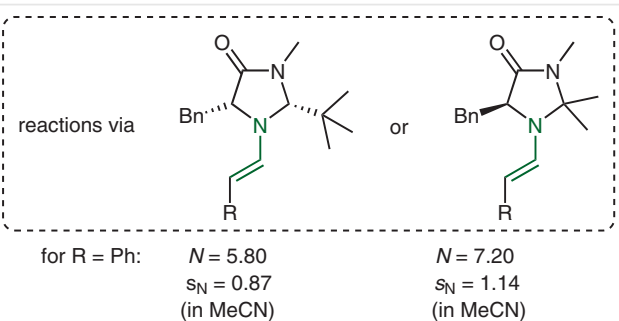

a)

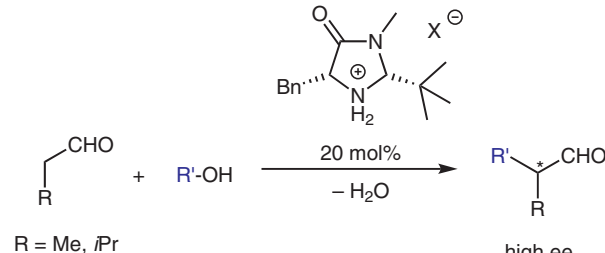

b)<smiles>O=CCC1CCCCC1</smiles><smiles>O=C1C(Cl)=C(Cl)C(Cl)=C(Cl)C1(Cl)Cl</smiles><smiles>CN1C(=O)C(Br)NC1(C)C</smiles><smiles>C[C@@H]1C[C@H](C(=O)O)[C@H]1C(=O)O</smiles><smiles>O=CC(Cl)C1CCCCC1</smiles>

25
$(E=-6.8$

Scheme 11 Organocatalytic $\alpha$-functionalizations of aldehydes via enamine intermediates according to (a) Cozzi (refs 67-70), and (b) MacMillan (ref 72)

a)<smiles>CCO/C=C(/C)C#N</smiles>

b)<smiles>C=COC</smiles><smiles>CC(C#N)=C(C#N)C#N</smiles>
$\overrightarrow{25{ }^{\circ} \mathrm{C}}$

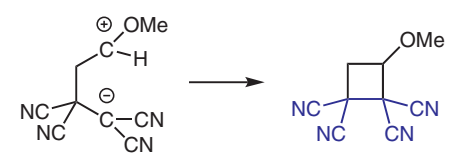

Scheme 12 (a) Comparison of the nucleophilicities of alkyl and silyl enol ethers, and (b) formation of cyclobutanes in the reaction of methyl vinyl ether with tetracyanoethene (from ref 76)

Lewis acid catalyzed additions of alkyl halides, acetals, and orthoesters to alkyl enol ethers only give 1:1 products when the reactants ionize more readily than the products. ${ }^{77-79}$ Though $\mathrm{ZnCl}_{2}$-catalyzed additions of $\alpha, \beta$-unsaturated acetals to ethyl vinyl ether are key steps in Isler's technical $\beta$-carotin synthesis, ${ }^{80}$ the choice of reactants, which ionize faster than the resulting $\alpha$-haloethers or acetals, is limited, ${ }^{81}$ as shown by the examples depicted in Scheme 13.

Silyl enol ethers, which are readily accessible from carbonyl compounds with high regio- and stereoselectivity, are more versatile reagents. ${ }^{83}$ Since $\alpha$-siloxy-carbenium ions generated by electrophilic attack at silyl enol ethers are 
a)<smiles>COc1ccc(C(Cl)c2ccc(C)cc2)cc1</smiles>
(for carbocation: $E=0.0$ )

b)<smiles>CCOC(C)CC(OC)c1ccccc1</smiles>
(for carbocation: $E=3.0$ )<smiles>C=COC(OCC)C(=CCC1=C(C)CCCC1(C)C)CC</smiles>

Scheme 13 Lewis acid catalyzed additions of alkoxycarbenium precursors to alkyl vinyl ethers: Example (a) from ref 82, example (b) from ref 78 , and example (c) from ref 80

rapidly desilylated to give carbonyl compounds, the problem of polymerization encountered with alkyl enol ethers is largely eliminated. However, only highly electrophilic Michael acceptors, like the bis(benzenesulfonyl)-substituted ethylene 20, undergo uncatalyzed reactions with silylated enol ethers (Scheme 14). ${ }^{43}$

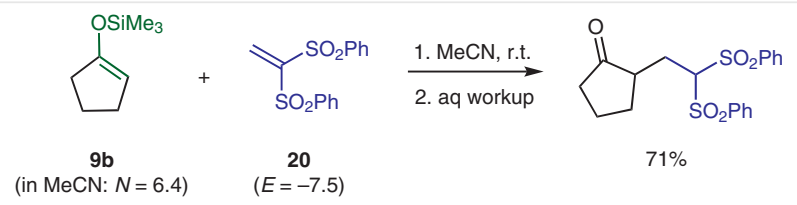

Scheme 14 Reaction of 1,1-bis(benzenesulfonyl)ethylene (20) with the silyl enol ether $\mathbf{9 b}$ (from ref 43 )

Reactions of silyl enol ethers with less reactive electrophiles, such as carbonyl compounds, $\alpha, \beta$-unsaturated ketones or alkyl acrylates, require activation..$^{83}$ For example, Lewis acids can be employed to enhance the reactivity of carbonyl compounds for their reactions with silyl enol ethers. This concept is widely used in Mukaiyama-type cross-aldol $^{84}$ and Michael reactions ${ }^{85}$ of silyl enol ethers as shown for the reactions of $\mathbf{9 b}$ in Scheme 15..$^{86-88}$

Alternatively, Lewis base catalysis ${ }^{89}$ was used to activate the nucleophile in Mannich-type reactions of silyl enol ethers with Schiff bases, such as PhCH=NTs (26). ${ }^{90,91}$ In these reactions, coordination of phthalimide or carboxylate anions at silicon is assumed to enhance the nucleophilicity of the silyl enol ether through the formation of hypervalent silicon species (Scheme 16a).91-93 Similarly, acetate ions triggered the Michael reactions of $\mathbf{1 b}$ and 1-(trimethylsiloxy)cyclohexene (9c) with chalcone (13) (Scheme 16b). ${ }^{94-96}$ a)

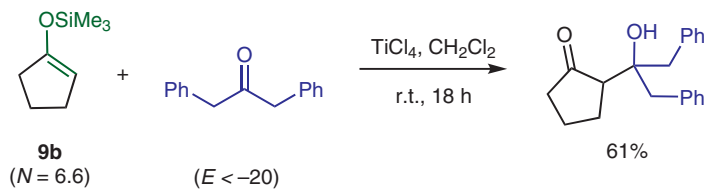

b)

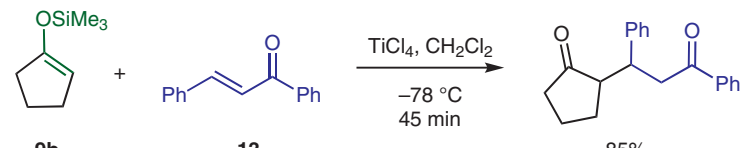

$$
\begin{array}{ccc}
9 \mathbf{b} & 13 & 85 \% \\
(N=6.6) & (E=-19.4) &
\end{array}
$$

Scheme 15 Titanium tetrachloride promoted Mukaiyama reactions of silyl enol ether $\mathbf{9 b}$ with (a) 1,3-diphenylacetone (from ref 84), and (b) chalcone (13) (from ref 85 ). In line with the reactivity parameters $N$ and $E$, no reaction is expected in the absence of the Lewis acidic catalyst

a)
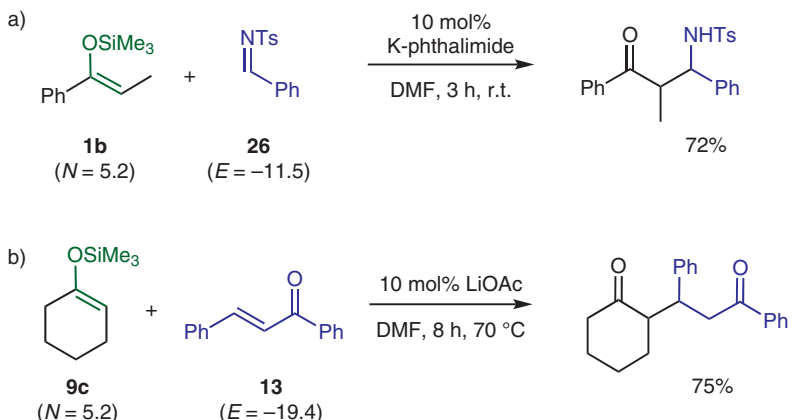

$75 \%$

Scheme 16 Lewis base catalyzed reactions of silyl enol ethers: (a) with imines (from ref 91), and (b) with $\alpha, \beta$-unsaturated ketones (from ref 94). In line with the reactivity parameters $N$ and $E$, no reaction is expected in the absence of the Lewis basic catalyst

Reetz reported the synthesis of $\alpha$-tert-alkyl-substituted carbonyl compounds by Lewis acid mediated reactions of silyl enol ethers with tert-alkyl chlorides or acetates (Scheme 17).97-99

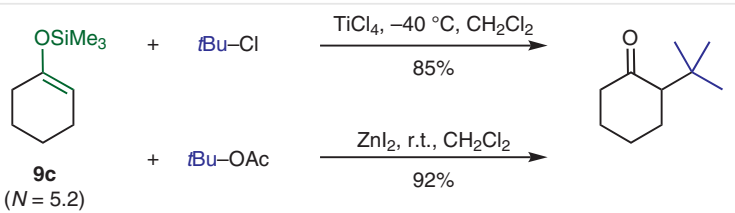

Scheme 17 Lewis acid mediated tert-butylation of the silyl enol ether 9c

As expected from their nucleophilicity parameters, silyl enol ethers react with iminium ions under mild conditions to give Mannich bases as illustrated in Scheme $18 a^{100-103}$ Important variants of this reaction are chiral-imidazolidinone-catalyzed reactions of $\alpha, \beta$-unsaturated aldehydes with silyl enol ethers to give $\delta$-ketoaldehydes in high yields and enantioselectivities (Scheme 18b). ${ }^{104,105}$ 
a)<smiles>C=[N+](C)O</smiles>
$(N=5.2)$ $(E=-6.7)$

b)

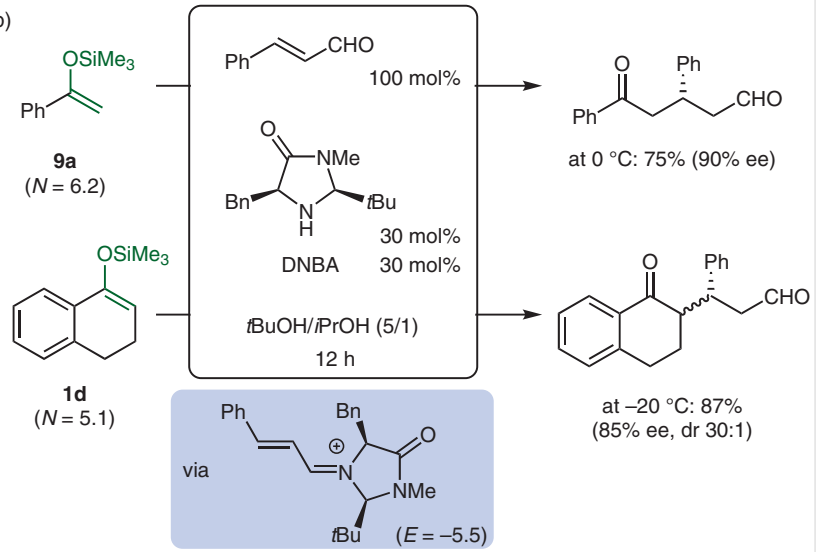

Scheme 18 Formation of (a) a Mannich base through the reaction of iminium ions with the silyl enol ether $\mathbf{9 c}$ (from ref 100 ), and (b) $\delta$-ketoaldehydes through iminium-activated reactions of cinnamaldehyde with the silyl enol ethers $\mathbf{9 a}$ and $\mathbf{1 d}$ (from ref 104) (DNBA = 2,4-dinitrobenzenesulfonic acid)

Silyl enol ethers readily react with the (tricarbonyl)ironcomplexed cyclohexadienylium (27) and the 2-phenyl[1,3]-dithian-2-ylium ion (28), which are positioned below most enol ethers in Figure 8 (Scheme 19). ${ }^{106-108}$ Highly reactive $\mathrm{Co}_{2}(\mathrm{CO})_{6}$-complexed propargyl cations (with $E$ in the range of +1 to $-1,{ }^{16}$ generated from the corresponding propargyl methyl ethers or acetates by $\mathrm{BF}_{3} \cdot \mathrm{OEt}_{2}$-mediated ionization) have been reported to react with the silyl enol ethers $\mathbf{1 b}$ and $\mathbf{9 c}$ even at $0{ }^{\circ} \mathrm{C}$ in dichloromethane to yield, after aqueous workup, $\alpha$-substituted ketones. ${ }^{109}$

Silyl enol ethers have also been used for the synthesis of $\alpha$-heteroatom-substituted carbonyl compounds. Slow reactions of silyl enol ethers 9a-c with diethyl diazocarboxylate $(29)^{110}$ are predicted by equation 1 . The observation that $\alpha-$ amino ketones formed slightly faster than predicted by equation 1 may be due to the fact that the electrophilic attack of the azodicarboxylate at the silylated enol ether is assisted by the interaction of the second nitrogen with silicon, thus giving rise to a concerted sila-Alder-ene reaction (Scheme 20). ${ }^{111,112}$

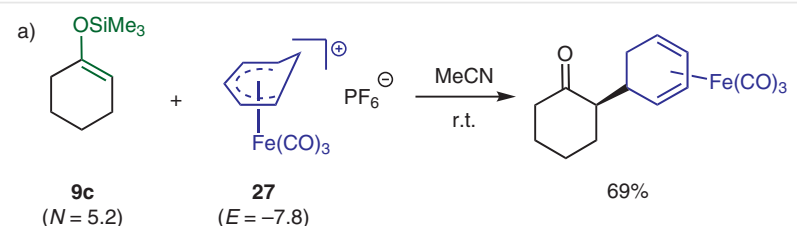

b)

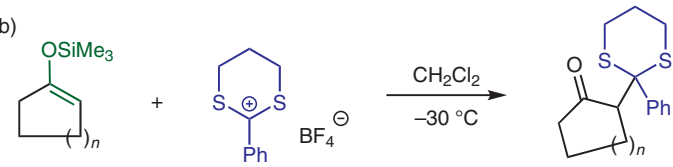
$9 \mathbf{b}(N=6.6)$
$9 \mathbf{c}(N=5.2)$
28
$(E=-6.4)$
from $9 \mathrm{~b}(n=1): 56 \%$ from $9 \mathrm{c}(n=2): 67 \%$

Scheme 19 Formation of $\alpha$-substituted ketones through reactions of silyl enol ethers with (a) (tricarbonyl)iron-stabilized cyclohexadienylium ions (from ref 106), and (b) [1,3]-dithian-2-ylium ions (from ref 108) (yields of isolated products after aqueous workup)
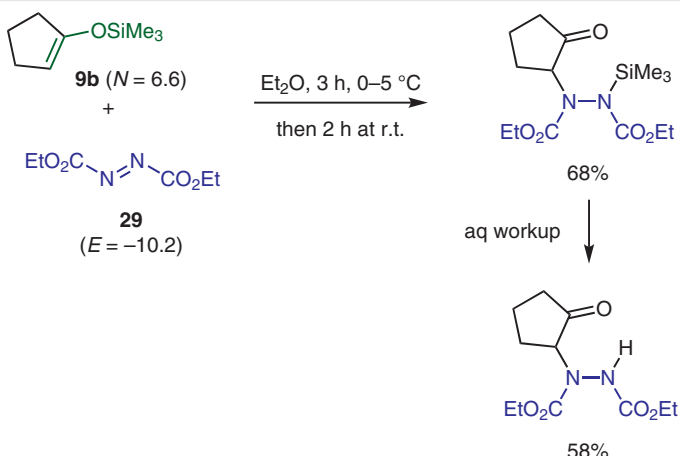

(72\% from $9 c, 56 \%$ from $9 a)$

Scheme 20 Uncatalyzed $\alpha$-amination of the silyl enol ether $\mathbf{9 b}$ by diethyl diazocarboxylate (29) (from ref 112)

Reactions of the $N$-fluoropyridinium triflate with silyl enol ethers are sluggish at room temperature and deliver $\alpha$ fluorinated products only after heating the reaction mixtures to reflux for several hours, ${ }^{113}$ in accord with the significantly lower nucleophilicities of silyl enol ethers compared to those of the structurally analogous enamines. The more electrophilic fluorinating and chlorinating reagents NFSI (22) $)^{114}$ and 2,3,4,5,6,6-hexachlorocyclohexa-2,4-dien1-one (25), ${ }^{73}$ respectively, with $E>-9$, are effective for the $\alpha$-halogenation of silyl enol ethers at ambient temperature (Scheme 21).

\section{Conclusion}

While studies on the chemistry of enolate anions started in the $19^{\text {th }}$ century, it was only in the second half of the $20^{\text {th }}$ century, particularly through the pioneering work of Stork and Mukaiyama, that the synthetic potential of enamines and silyl enol ethers became obvious. It was soon rec- 
a)

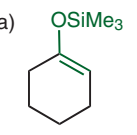

$9 c$
$(N=5.2)$

b)

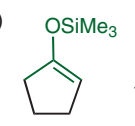

$\mathrm{F}_{\mathrm{N}}-\mathrm{SO}_{2} \mathrm{Ph}$
$\mathrm{I}$
$\mathrm{SO}_{2} \mathrm{Ph}$



22
$(E=-8.4)$

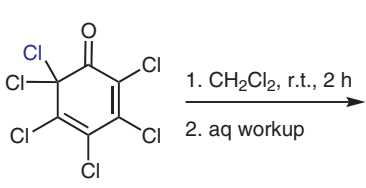

$(E=-6.8)$

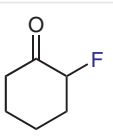

$46 \%$

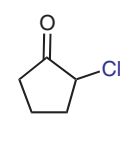

$55 \%$
Scheme 21 Formation of $\alpha$-haloketones by reactions of silyl enol ethers with the electrophilic reagents (a) NFSI (22) (from ref 114), and (b) 25 (from ref 73)

ognized that the lower nucleophilicities of these enolate equivalents enabled synthetic transformations that were not possible with enolate anions. While the qualitative ordering of reactivities of these compounds has long been known, we have now used the method of overlapping correlation lines for a quantitative comparison.

Kinetic investigations of ${ }^{-\mathrm{O}^{-}},-\mathrm{N}\left(\mathrm{CH}_{2}\right)_{4}{ }^{-}$and $-\mathrm{OSiMe}_{3}{ }^{-}$ substituted stilbenes with $\mathrm{C}$-centered electrophiles have shown that these structurally analogous enolate anions, enamines, and silyl enol ethers have relative reactivities of $10^{14}: 10^{7}: 1$. Since the measured second-order rate constants followed equation 1 , we were able to derive their nucleophile-specific parameters $N$ and $s_{\mathrm{N}}$. In combination with the more than 300 reported electrophilicity parameters $E,{ }^{16}$ equation 1 can now be used to predict the rates for a large variety of reactions of enolate anions and their synthetic equivalents with electrophiles. Of course, the concentrations of the enolate ions and enamines have to be considered when they are formed as intermediates in catalyzed reactions. Since the susceptibilities $s_{\mathrm{N}}$ of enolate anions, enamines, and enol ethers do not differ significantly, the synthetic potential of these reagents can be illustrated as shown in Figure 8: Enolate ions and their synthetic equivalents can be expected to react at room temperature with all electrophiles located below them in Figure 8.

\section{Funding Information}

Deutsche Forschungsgemeinschaft (SFB 749, project B1).

\section{Acknowledgment}

We are grateful to Nathalie Hampel for synthesizing the reference electrophiles and to Robert J. Mayer for quantum chemical calculations. We thank Professor Hans-Ulrich Reißig and Dr. Sami Lakhdar for helpful discussions.

\section{Supporting Information}

Supporting information for this article is available online at https://doi.org/10.1055/s-0037-1611634.

\section{References}

(1) Current affiliation: School of Chemistry, Joseph Black Building, University of Glasgow, University Avenue, Glasgow, G12 8QQ UK.

(2) Caine, D. Alkylations of Enols and Enolates, In Comprehensive Organic Synthesis, Vol. 3; Trost, B. M.; Fleming, I.; Pattenden, G., Ed.; Chap. 1.1; Pergamon Press: Oxford, 1991, 1-63.

(3) Stolz, D.; Kazmaier, U. Metal Enolates as Synthons in Organic Chemistry, In The Chemistry of Metal Enolates Part 1; Zabicky, J., Ed.; Wiley: Chichester, 2009, Chap. 7, 355-410.

(4) Bruckner, R. Chemistry of the Alkaline Earth Metal Enolates, In Organic Mechanisms - Reactions, Stereochemistry and Synthesis; Harmata, M., Ed.; Springer-Verlag: Berlin, 2010, Chap. 13, 519593.

(5) Bates, R. B.; Ogle, C. A. Carbanion Chemistry; Springer: Berlin, 1983.

(6) Brandsma, L. Preparative Polar Organometallic Chemistry, Vol. 2; Springer: Berlin, 1990, 1-13.

(7) Jung, M. E. Stabilized Nucleophiles with Electron Deficient Alkenes and Alkynes, In Comprehensive Organic Synthesis, Vol. 4; Trost, B. M.; Fleming, I.; Semmelhack, M. F., Ed.; Chap. 1.1; Pergamon Press: Oxford, 1991, 1-67.

(8) Snieckus, V. Advances in Carbanion Chemistry; Snieckus, V., Ed.; JAI Press: Greenwich (CT), 1992.

(9) Buncel, E.; Dust, J. M. Carbanion Chemistry; Oxford University Press: Oxford, 2003.

(10) Smith, M. B. In March's Advanced Organic Chemistry: Reactions, Mechanisms, and Structure; John Wiley \& Sons: Hoboken, 2013, 7th Ed., 221-233.

(11) Minko, Y.; Marek, I. Chem. Commun. 2014, 50, 12597.

(12) Mayr, H.; Bug, T.; Gotta, M. F.; Hering, N.; Irrgang, B.; Janker, B.; Kempf, B.; Loos, R.; Ofial, A. R.; Remennikov, G.; Schimmel, H. J. Am. Chem. Soc. 2001, 123, 9500.

(13) Lucius, R.; Loos, R.; Mayr, H. Angew. Chem. Int. Ed. 2002, 41, 91; Angew. Chem. 2002, 114, 97.

(14) Mayr, H. Tetrahedron 2015, 71, 5095.

(15) Mayr, H.; Ofial, A. R. SAR QSAR Environ. Res. 2015, 26, 619.

(16) For a freely accessible database of $E, N$, and $s_{\mathrm{N}}$ parameters, see: http://www.cup.lmu.de/oc/mayr/DBintro.html (accessed Dec 12, 2018).

(17) Richter, D.; Hampel, N.; Singer, T.; Ofial, A. R.; Mayr, H. Eur. J. Org. Chem. 2009, 3203.

(18) Follet, E.; Berionni, G.; Mayer, P.; Mayr, H.J. Org. Chem. 2015, 80, 8643.

(19) Kempf, B.; Hampel, N.; Ofial, A. R.; Mayr, H. Chem. Eur. J. 2003, 9 , 2209.

(20) Derived from molecular geometries calculated using the $\mathrm{SMD}$ (acetonitrile)/M06-2X/6-31+g(d,p) level of theory.

(21) Kanzian, T.; Lakhdar, S.; Mayr, H. Angew. Chem. Int. Ed. 2010, 49, 9526.

(22) Corral Bautista, F.; Appel, R.; Frickel, J. S.; Mayr, H. Chem. Eur. J. 2015, 21, 875 .

(23) Timofeeva, D. S.; Mayer, R. J.; Mayer, P.; Ofial, A. R.; Mayr, H. Chem. Eur. J. 2018, 24, 5901.

(24) Denmark, S. E.; Stavenger, R. A. Acc. Chem. Res. 2000, 33, 432. 
(25) Palomo, C.; Oiarbide, M.; Garcia, J. M. Chem. Soc. Rev. 2004, 33, 65.

(26) Schetter, B.; Mahrwald, R. Angew. Chem. Int. Ed. 2006, 45, 7506.

(27) Valnot, J.-Y.; Maddaluno, J. In The Chemistry of Organolithium Compounds, Vol 2; Rappoport, Z.; Marek, I., Ed.; Chap. 8; Wiley: Chichester, 2006, 525-646.

(28) Bertrand, J.; Gorrichon, L.; Maroni, P. Tetrahedron 1984, 40, 4127.

(29) For a discussion of the ambident reactions of enolate ions, see: Mayr, H.; Breugst, M.; Ofial, A. R. Angew. Chem. Int. Ed. 2011, 50, 6470.

(30) Juaristi, E.; Beck, A. K.; Hansen, J.; Matt, T.; Mukhopadhyay, T.; Simson, M.; Seebach, D. Synthesis 1993, 1271.

(31) Shankar, R.; Jha, A. K.; Singh, U. S.; Hajela, K. Tetrahedron Lett. 2006, 47, 3077.

(32) For a review on the use of $\mathrm{K}_{2} \mathrm{CO}_{3}$ for the generation of enolate ions in synthetic applications, see: Khachatryan, D. S.; Matevosyan, K. R. Russ. Chem. Bull. 2016, 65, 14.

(33) Lee, V. J. Conjugate Additions of Reactive Carbanions to Activated Alkenes and Alkynes, In Comprehensive Organic Synthesis, Vol 4; Trost, B. M.; Fleming, I.; Semmelhack, M. F., Ed.; Chap. 1.2; Pergamon Press: Oxford, 1991, 69-137.

(34) Shrout, D. P.; Lightner, D. A. Synthesis 1990, 1062.

(35) Unsworth, W. P.; Coulthard, G.; Kitsiou, C.; Taylor, R. J. K. J. Org. Chem. 2014, 79, 1368.

(36) For examples of (3+2)-cycloadduct synthesis, see: (a) Tsuge, O.; Kanemasa, S.; Takenaka, S. Bull. Chem. Soc. Jpn. 1985, 58, 3137. (b) Tsuge, O.; Kanemasa, S.; Takenaka, S. Bull. Chem. Soc. Jpn. 1985, 58, 3320. (c) Shestopalov, A. M.; Sharanin, Y. A.; Nesterov, V. N.; Rodinovskaya, L. A.; Shklover, V. E.; Struchkov, Y. T.; Litvinov, V. P. Chem. Heterocycl. Compd. 1991, 27, 1006.

(37) Allgäuer, D. S.; Jangra, H.; Asahara, H.; Li, Z.; Chen, Q.; Zipse, H.; Ofial, A. R.; Mayr, H. J. Am. Chem. Soc. 2017, 139, 13318.

(38) For examples of cyclopropanations, see: (a) Shestopalov, A. M.; Litvinov, V. P.; Rodinovskaya, L. A.; Sharanin, Y. A. Bull. Acad. Sci. USSR, Div. Chem. Sci. (Engl. Transl.) 1991, 40, 129. (b) Vo, N. H.; Eyermann, C. J.; Hodge, C. N. Tetrahedron Lett. 1997, 38, 7951. (c) Kojima, S.; Fujitomo, K.; Shinohara, Y.; Shimizu, M.; Ohkata, K. Tetrahedron Lett. 2000, 41, 9847. (d) Yamada, S.; Yamamoto, J.; Ohta, E. Tetrahedron Lett. 2007, 48, 855. (e) Wang, Q.-F.; Song, X.-K.; Chen, J.; Yan, C.-G. J. Comb. Chem. 2009, 11, 1007.

(39) For a review on related cyclopropanations of ammonium ylides, see: Roiser, L.; Zielke, K.; Waser, M. Asian J. Org. Chem. 2018, 7, 852.

(40) Allgäuer, D. S.; Mayer, P.; Mayr, H. J. Am. Chem. Soc. 2013, 135, 15216

(41) Stork, G.; Brizzolara, A.; Landesman, H.; Szmuszkovicz, J.; Terrell, R. J. Am. Chem. Soc. 1963, 85, 207.

(42) (a) Dyke, S. F. The Chemistry of Enamines; Cambridge University Press: Cambridge, 1973. (b) Hickmott, P. W. Tetrahedron 1982, 38, 1975. (c) Hickmott, P. W. Tetrahedron 1982, 38, 3363. (d) Alt, G. H.; Cook, A. G. Enamines: Synthesis, Structure, and Reactions; Cook, A. G., Ed.; Marcel Dekker Inc: New York, 1988, Chap. 4.

(43) Asahara, H.; Mayr, H. Chem. Asian J. 2012, 7, 1401.

(44) (a) Birkofer, L.; Kim, S. M.; Engels, H. D. Chem. Ber. 1962, 95, 1495. (b) Lewis, J. W.; Myers, P. L.; Readhead, M. J.J. Chem. Soc. C 1970, 771. (c) Katsin, N.; Ikan, R. Synth. Commun. 1977, 7, 185.

(45) (a) Risch, N.; Esser, A. Z. Naturforsch., B: Chem. Sci. 1989, 44, 208. (b) Mölm, D.; Flörke, U.; Risch, N. Eur. J. Org. Chem. 1998, 2185.

(46) For stereoselective reactions of enamines with iminium ions (at r.t. in $\mathrm{MeCN}$ ), see: Kossenjans, M.; Martens, J. Tetrahedron: Asymmetry 1999, 10, 3409.
(47) Timofeeva, D. S.; Ofial, A. R.; Mayr, H. J. Am. Chem. Soc. 2018, $140,11474$.

(48) Zhang, J.; Yang, J.-D.; Zheng, H.; Xue, X.-S.; Mayr, H.; Cheng, J.-P. Angew. Chem. Int. Ed. 2018, 57, 12690.

(49) List, B. Acc. Chem. Res. 2004, 37, 548.

(50) Mukherjee, S.; Yang, J. W.; Hoffmann, S.; List, B. Chem. Rev. 2007, 107, 5471.

(51) Pihko, P. M.; Majander, I.; Erkkilä, A. Enamine Catalysis, In Asymmetric Catalysis; List, B., Ed.; Springer: Heidelberg, 2009, 145200.

(52) Waser, M. Asymmetric Organocatalysis in Natural Product Syntheses; Springer: Wien, 2012, 7-44.

(53) Mayr, H.; Lakhdar, S.; Maji, B.; Ofial, A. R. Beilstein J. Org. Chem. 2012, 8, 1458 .

(54) Jiang, H.; Albrecht, Ł.; Dickmeiss, G.; Jensen, K. L.; Jørgensen, K. A. TMS-Prolinol Catalyst in Organocatalysis, In Comprehensive Enantioselective Organocatalysis, Vol 1; Dalko, P. I., Ed.; Chap. 2; Wiley-VCH: Weinheim, 2013, 33-50.

(55) Mahrwald, R. Chiral Imidazolidinone (MacMillan's) Catalyst, In Comprehensive Enantioselective Organocatalysis, Vol 1; Dalko, P. I., Ed.; Chap. 4; Wiley-VCH: Weinheim, 2013, 69-96.

(56) Hansen, J. H.; Zeeshan, M. Mini-Rev. Org. Chem. 2014, 11, 432.

(57) List, B.; Lerner, R. A.; Barbas III, C. F. J. Am. Chem. Soc. 2000, 122, 2395.

(58) List, B.; Pojarliev, P.; Castello, C. Org. Lett. 2001, 3, 573.

(59) (a) List, B. J. Am. Chem. Soc. 2000, 122, 9336. (b) List, B.; Pojarliev, P.; Biller, W. T.; Martin, H. J. J. Am. Chem. Soc. 2002, $124,827$.

(60) List, B.; Pojarliev, P.; Martin, H. J. Org. Lett. 2001, 3, 2423.

(61) Mielgo, A.; Palomo, C. Chem. Asian J. 2008, 3, 922.

(62) Jensen, K. L.; Dickmeiss, G.; Jiang, H.; Albrecht, Ł.; Jørgensen, K. A. Acc. Chem. Res. 2012, 45, 248.

(63) Lakhdar, S.; Maji, B.; Mayr, H. Angew. Chem. Int. Ed. 2012, 51, 5739.

(64) Hayashi, Y.; Gotoh, H.; Hayashi, T.; Shoji, M. Angew. Chem. Int. Ed. 2005, 44, 4212.

(65) Roux, C.; Bressy, C. Addition to Nitroolefins and Vinyl Sulfones, In Comprehensive Enantioselective Organocatalysis, Vol 3; Dalko, P. I., Ed.; Chap. 34; Wiley-VCH: Weinheim, 2013, 1013-1042.

(66) For the use of further secondary amines as catalysts for this Michael addition, see: Melchiorre, P.; Jørgensen, K. A. J. Org. Chem. 2003, 68, 4151.

(67) (a) Cozzi, P. G.; Benfatti, F.; Zoli, L. Angew. Chem. Int. Ed. 2009, 48, 1313. (b) Gualandi, A.; Emer, E.; Guiteras Capdevila, M.; Cozzi, P. G. Angew. Chem. Int. Ed. 2011, 50, 7842.

(68) Benfatti, F.; Benedetto, E.; Cozzi, P. G. Chem. Asian J. 2010, 5, 2047.

(69) Gualandi, A.; Petruzziello, D.; Emer, E.; Cozzi, P. G. Alpha-Alkylation by $S_{N} 1$-Type Reactions, In Comprehensive Enantioselective Organocatalysis, Vol 3; Dalko, P. I., Ed.; Chap. 26; Wiley-VCH: Weinheim, 2013, 729-756.

(70) (a) Gualandi, A.; Mengozzi, L.; Giacoboni, J.; Saulnier, S.; Ciardi, M.; Cozzi, P. G. Chirality 2014, 26, 607. (b) Gualandi, A.; Mengozzi, L.; Manoni, E.; Cozzi, P. G. Chem. Rec. 2016, 16, 1228.

(71) Beeson, T. D.; MacMillan, D. W. C. J. Am. Chem. Soc. 2005, 127, 8826.

(72) Brochu, M. P.; Brown, S. P.; MacMillan, D. W. C. J. Am. Chem. Soc. 2004, 126, 4108.

(73) Duan, X.-H.; Mayr, H. Org. Lett. 2010, 12, 2238.

(74) Mayr, H.; Kempf, B.; Ofial, A. R. Acc. Chem. Res. 2003, 36, 66.

(75) Hall, H. K. Jr. Angew. Chem., Int. Ed. Engl. 1983, 22, 440.

(76) Huisgen, R. Acc. Chem. Res. 1977, 10, 117.

(77) Mayr, H. Angew. Chem., Int. Ed. Engl. 1981, 20, 184. 
(78) Mayr, H.; Striepe, W. J. Org. Chem. 1983, 48, 1159.

(79) von der Brüggen, U.; Lammers, R.; Mayr, H. J. Org. Chem. 1988, $53,2920$.

(80) Isler, O.; Lindlar, H.; Montavon, M.; Rüegg, R.; Zeller, P. Helv. Chim. Acta 1956, 39, 249.

(81) The synthetic scope of the reactions of acetals with alkyl enol ethers is demonstrated in the articles quoted in ref 79.

(82) Burfeindt, J.; Patz, M.; Müller, M.; Mayr, H. J. Am. Chem. Soc. 1998, 120, 3629.

(83) Brownbridge, P. Synthesis 1983, 1.

(84) Mukaiyama, T.; Narasaka, K.; Banno, K. Chem. Lett. 1973, 2, 1011.

(85) Narasaka, K.; Soai, K.; Mukaiyama, T. Chem. Lett. 1974, 3, 1223.

(86) Mukaiyama, T. Angew. Chem., Int. Ed. Engl. 1977, 16, 817.

(87) Mukaiyama, T. Pure Appl. Chem. 1983, 44, 1749.

(88) Matsuo, J.-i.; Murakami, M. Angew. Chem. Int. Ed. 2013, 52, 9109.

(89) Lewis Base Catalysis in Organic Synthesis; Vedejs, E.; Denmark, S. E., Ed.; Wiley-VCH: Weinheim, 2016.

(90) (a) Takahashi, E.; Fujisawa, H.; Mukaiyama, T. Chem. Lett. 2004, 33, 1426. (b) Takahashi, E.; Fujisawa, H.; Mukaiyama, T. Chem. Lett. 2005, 34, 84.

(91) Fujisawa, H.; Takahashi, E.; Mukaiyama, T. Chem. Eur.J. 2006, 12, 5082.

(92) Rendler, S.; Oestreich, M. Synthesis 2005, 1727.

(93) Denmark, S. E.; Beutner, G. L. Angew. Chem. Int. Ed. 2008, 47, 1560.

(94) Nakagawa, T.; Fujisawa, H.; Nagata, Y.; Mukaiyama, T. Chem. Lett. 2004, 33, 1016.

(95) Gawronski, J.; Wascinska, N.; Gajewy, J. Chem. Rev. 2008, 108, 5227.
(96) Frías, M.; Cieślik, W.; Fraile, A.; Rosado-Abón, A.; GarridoCastro, A. F.; Yuste, F.; Alemán, J. Chem. Eur. J. 2018, 24, 10906.

(97) Reetz, M. T.; Maier, W. F. Angew. Chem., Int. Ed. Engl. 1978, 17, 48.

(98) Reetz, M. T.; Hüttenhain, S.; Hübner, F. Synth. Commun. 1981, $11,217$.

(99) Reetz, M. T. Angew. Chem., Int. Ed. Engl. 1982, 21, 96.

(100)Danishefsky, S.; Kitahara, T.; McKee, R.; Schuda, P. F. J. Am. Chem. Soc. 1976, 98, 6715.

(101) Tramontini, M.; Angiolini, L. Tetrahedron 1990, 46, 1791.

(102) Arend, M.; Westermann, B.; Risch, N. Angew. Chem. Int. Ed. 1998, 37, 1044.

(103) Merino, P. Mannich-Type Reactions, In Science of Synthesis: C-1 Building Blocks in Organic Synthesis; van Leeuwen, P. W. N. M., Ed.; Thieme Verlag: Stuttgart, 2014, Vol 2, 311-331.

(104)Wang, W.; Li, H.; Wang, J. Org. Lett. 2005, 7, 1637.

(105) Erkkilä, A.; Majander, I.; Pihko, P. M. Chem. Rev. 2007, 107, 5416.

(106) Birch, A. J.; Kelly, L. F.; Narula, A. S. Tetrahedron 1982, 38, 1813.

(107) Stahl, I. Chem. Ber. 1985, 118, 1798.

(108) Mayr, H.; Henninger, J.; Siegmund, T. Res. Chem. Intermed. 1996, $22,821$.

(109) Guo, R.; Gibe, R.; Green, J. R. Can. J. Chem. 2004, 82, 366.

(110) Kanzian, T.; Mayr, H. Chem. Eur. J. 2010, 16, 11670.

(111) Gilmore, K.; Manoharan, M.; Wu, J. I.-C.; Schleyer, P. v. R.; Alabugin, I. V. J. Am. Chem. Soc. 2012, 134, 10584.

(112) Moriarty, R. M.; Prakash, I. Synth. Commun. 1985, 15, 649.

(113) Umemoto, T.; Fukami, S.; Tomizawa, G.; Harasawa, K.; Kawada, K.; Tomita, K. J. Am. Chem. Soc. 1990, 112, 8563.

(114) Differding, E.; Ofner, H. Synlett 1991, 187. 